\title{
Targeting intrinsically disordered proteins involved in cancer
}

\author{
Patricia Santofimia-Castaño ${ }^{1}$ - Bruno Rizzuti ${ }^{2} \cdot$ Yi Xia $^{3}$ - Olga Abian ${ }^{4,5,6,7,8} \cdot$ Ling Peng $^{9}$. \\ Adrián Velázquez-Campoy ${ }^{4,5,6,7,10} \cdot$ José L. Neira ${ }^{4,11}$ (1) J Juan lovanna ${ }^{1}$ (]
}

Received: 5 August 2019 / Revised: 23 September 2019 / Accepted: 16 October 2019 / Published online: 30 October 2019 (c) The Author(s) 2019

\begin{abstract}
Intrinsically disordered proteins (IDPs) do not have a well-defined structure under physiological conditions, but they have key roles in cell signaling and regulation, and they are frequently related to the development of diseases, such as cancer and other malignancies. This has converted IDPs in attractive therapeutic targets; however, targeting IDPs is challenging because of their dynamic nature. In the last years, different experimental and computational approaches, as well as the combination of both, have been explored to identify molecules to target either the hot-spots or the allosteric sites of IDPs. In this review, we summarize recent developments in successful targeting of IDPs, all of which are involved in different cancer types. The strategies used to develop and design (or in one particular example, to repurpose) small molecules targeting IDPs are, in a global sense, similar to those used in well-folded proteins: (1) screening of chemically diverse or target-oriented compound libraries; or (2) study of the interfaces involved in recognition of their natural partners, and design of molecular candidates capable of binding to such binding interface. We describe the outcomes of using these approaches in targeting IDPs involved in cancer, in the view to providing insight, to target IDPs in general. In a broad sense, the designed small molecules seem to target the most hydrophobic regions of the IDPs, hampering macromolecule (DNA or protein)-IDP interactions; furthermore, in most of the molecule-IDP complexes described so far, the protein remains disordered.
\end{abstract}

Keywords Cancer · Drug design · Protein function · Intrinsically disordered protein · NUPR1 · Stress response · Pancreatic ductal adenocarcinoma $\cdot$ Protein-protein interactions

José L. Neira

jlneira@umh.es

$\triangle$ Juan Iovanna

juan.iovanna@inserm.fr

1 Centre de Recherche en Cancérologie de Marseille (CRCM), INSERM U1068, CNRS, UMR 7258, Aix-Marseille Université and Institut Paoli-Calmettes, Parc Scientifique et Technologique de Luminy, 163 Avenue de Luminy, 13288 Marseille, France

2 CNR-NANOTEC, Licryl-UOS Cosenza and CEMIF.Cal, Department of Physics, University of Calabria, Via P. Bucci, Cubo 31 C, Arcavacata di Rende, 87036 Cosenza, Italy

3 Chongqing Key Laboratory of Natural Product Synthesis and Drug Research, School of Pharmaceutical Sciences, Chongqing University, No. 55 Daxuecheng South Road, Chongqing 401331, People's Republic of China

4 Instituto de Biocomputación y Física de Sistemas Complejos (BIFI), Joint Units IQFR-CSIC-BIFI, and GBsC-CSIC-BIFI, Universidad de Zaragoza, 50009 Zaragoza, Spain
5 Aragon Institute for Health Research (IIS Aragon), Zaragoza, Spain

6 Centro de Investigación Biomédica en Red en el Área Temática de Enfermedades Hepáticas y Digestivas (CIBERehd), Madrid, Spain

7 Departamento de Bioquímica y Biología Molecular y Celular, Universidad de Zaragoza, 50009 Zaragoza, Spain

8 Instituto Aragonés de Ciencias de la Salud (IACS), 50009 Zaragoza, Spain

9 Aix-Marseille Université, CNRS, Centre Interdisciplinaire de Nanoscience de Marseille, UMR 7325, Equipe Labellisée Ligue Contre le Cancer, Parc Scientifique et Technologique de Luminy, 163 Avenue de Luminy, 13288 Marseille, France

10 Fundacion ARAID, Government of Aragon, 50018 Zaragoza, Spain

11 Instituto de Biología Molecular y Celular, Universidad Miguel Hernández, Avda. del Ferrocarril s/n, Elche, 03202 Alicante, Spain 


$\begin{array}{ll}\text { Abbreviations } \\ \text { CD } & \text { Circular dichroism } \\ \text { cdk } & \text { Cyclin-dependent kinase } \\ \text { C-PTP1B } & \begin{array}{l}\text { Disordered C-terminal region of protein tyros- } \\ \text { ine phosphatase 1B }\end{array} \\ \text { EFP } & \text { Ewing's fusion protein } \\ \text { EWS } & \text { Ewing's sarcoma oncoprotein } \\ \text { FRET } & \text { Fluorescence resonance energy transfer } \\ \text { HER2 } & \text { Human epidermal growth factor receptor 2 } \\ \text { ID } & \text { Intrinsically disordered } \\ \text { IDP } & \text { Intrinsically disordered protein } \\ \text { ITC } & \text { Isothermal titration calorimetry } \\ \text { KID } & \text { Kinase inhibitory domain } \\ \text { LDH } & \text { Lactate dehydrogenase } \\ \text { MD } & \text { Molecular dynamics } \\ \text { MDM2 } & \text { Murine double minute 2 } \\ \text { MLL } & \text { Mixed lineage leukemia } \\ \text { NMR } & \text { Nuclear magnetic resonance } \\ \text { NUPR1 } & \text { Nuclear protein 1 } \\ \text { p53-TA } & \text { The TA of p53, comprising residues 1-61 of } \\ & \text { the whole intact p53 protein } \\ \text { PDAC } & \text { Pancreatic ductal adenocarcinoma } \\ \text { PP } & \text { Protein-protein } \\ \text { PPI } & \text { Protein-protein interaction } \\ \text { PTP1B } & \text { Protein tyrosine phosphatase 1B } \\ \text { ROS } & \text { Reactive oxygen species } \\ \text { SAXS } & \text { Small-angle X-ray scattering } \\ \text { SEC } & \text { Size-exclusion chromatography } \\ \text { SPR } & \text { Surface plasmon resonance } \\ \text { TA } & \text { Transcriptional activation domain } \\ \text { TF } & \text { Transcription factor } \\ \text { TFP } & \text { Trifluoperazine } \\ \text { TYH } & \text { Two-yeast hybrid } \\ & \end{array}$

\section{Introduction}

Intrinsically disordered proteins (IDPs) do not have distinct, well-defined secondary and tertiary structures, because of their remarkable backbone flexibility $[1,2]$. Their sequence has a large percentage of charged and polar residues, and a low percentage of hydrophobic, bulky side-chains [2]. IDPs are present in many organisms and their proportion increases from bacteria to higher species [3]. In fact, IDPs involved in gene regulation, protein networks, and cell signaling are over-represented, and therefore, they have been considered during the last decade as potential drug targets [4]. For instance, approximately $70 \%$ of human cancerassociated proteins have been predicted to contain relatively long unstructured regions [3, 5]. Unfolded regions in those proteins are involved in protein-protein (PP) or other biomolecular interactions, interacting with different partners in many-to-one and one-to-many binding equilibria (i.e., acting as "hubs") [6]. Furthermore, they can also bind to their partners in different conformations or cause dissociation (the so-called "moonlighting" [7]). Their highly flexible nature makes them suitable for post-translational modification, and, in fact, they are often involved in phosphorylation pathways $[7,8]$.

During the binding of an IDP to a macromolecule (usually another protein), large interfaces are involved, resulting in very specific, but comparatively weak, interactions $[8,9]$ : the appropriate partner provides the required complementary surface generating sufficient enthalpy gain to compensate for the loss of entropy occurring upon binding. However, when we design a small molecule, capable of binding the IDP, hampering its protein-protein interactions (PPIs), the understanding of the thermodynamics of the binding reaction is mostly lacking, since the designed compound does not usually have a large interface to interact with. Targeting the PP interface of an IDP with small designed molecules can be envisioned from two general perspectives. First, specific short regions of the intrinsically disordered (ID) sequence, which are known (or predicted) to be involved in binding, are matched by structure-based rationally designed small molecules. These molecules will replace the recognition region of the IDP in the binding to its partners [10]. The second perspective is achieved when a small molecule, identified by a particular screening protocol, binds to a segment of the IDP (usually, but not always, the hot-spot region, as discussed in the sections below); this second approach involves a "fishing" protocol similar to those used for the drug screening on well-folded proteins [11] (Fig. 1). In both approaches,

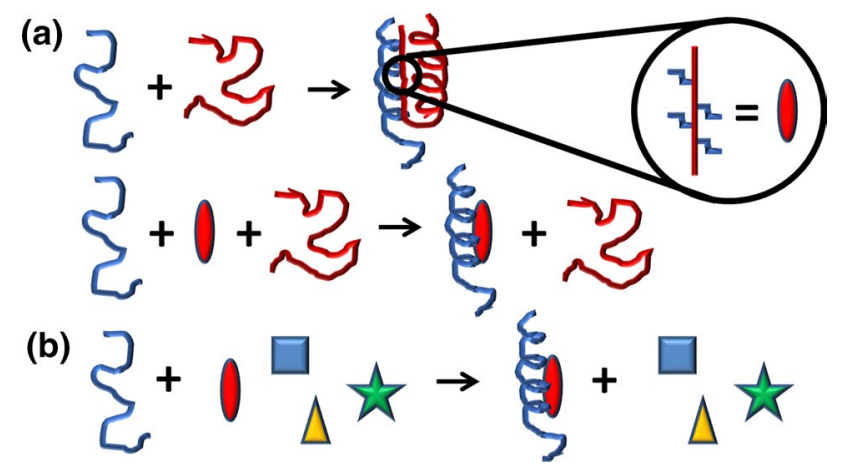

Fig. 1 The two approaches used in screening IDPs. The red oval indicates the molecule that binds to the PP interface of the target IDP (in blue), and it is designed based on the structural features of the partner protein, which, in our example, is another IDP (in red), but it could be a well-folded protein (a). In the second approach (b), a library of different compounds (represented as shapes with different colors) is used to find out whether one of them is captured by the IDP (in our example the red oval again). In both examples, we have assumed that the IDP folds after binding to the molecule, but it could also remain disordered upon binding 
the local nature of the binding interactions with the small molecule reduces the chain entropic costs associated with the folding-upon-binding reaction that takes place usually for most of the IDPs. In addition, the last approach may lead to a competitive small molecule directly blocking the binding region in the IDP (orthosteric binding) or to a noncompetitive small molecule binding to another binding site (allosteric binding) in the IDP, trapping the IDP into an inactive conformation by hindering its required functional conformational change. The relative importance of the desolvation entropy contribution (entropic gain favoring the binding originated by the hydrophobic effect and related to the release of water molecules from the binding interface to the bulk solution) and the conformational entropy contribution (entropic loss opposing the binding associated with the change in degrees of freedom of structural elements of the interacting molecules, as a result of the multimolecular assembly along the binding process) is difficult to predict or estimate. The desolvation entropy gain depends on: (1) the amount of hydrophobic groups located in the binding interface; and (2) the net number of water molecules released upon binding. The conformational entropy loss depends on: (1) the degree and extent of flexibility of both interacting molecules; and (2) their structural disorder before and after the binding process. If a disordered protein, interacting with a binding partner, undergoes a global folding, as a result of the interaction leading to a well-defined ordered binding interface, the conformational entropy loss will be larger than that for a disordered protein that only folds locally or even remains globally unstructured upon binding and establishes a fuzzy complex with the binding partner.

In this review, we provide and discuss recent examples of IDPs, involved at different stages in several kinds of cancers, which have been successfully targeted by small molecules. We aim to obtain general conclusions on the current protocols used in targeting IDPs and to foresee future approaches and developments. The mechanisms by which the molecules act seem to be similar in most of the assayed IDPs: that is, hampering PP, or DNA-protein, interactions, mainly taking advantage of hydrophobic effects, although the fine details are protein-dependent (and then, cancer-dependent). Most of the successfully targeted IDPs are implicated in cellular stress mechanisms. Cancer cells, in general, grow under a hypoxic microenvironment, with low contribution of nutrients, high mechanic strain, and various other constraining conditions, which activate stress proteins $[12,13]$. Stress protein-dependent mechanisms can help cancer cells to adapt to such harsh environmental conditions. Thus, cancer cells growing under stress conditions become highly dependent on the function of those stress proteins which are mainly ID [14].

\section{Targeted IDPs involved in cancer}

\section{The c-Myc/Max system: blocking IDP hetero-dimer structure and function}

The oncogenic transcription factor (TF) c-Myc is involved in cell growth, apoptosis, and metabolic processes $[15,16]$. Structurally, it is composed by two independent regions: an $\mathrm{N}$-terminal transactivating domain and a C-terminal helixloop-helix leucine zipper region (Fig. 2). The c-Myc binds through the latter polypeptide patch to the partner protein Max, which uses a similar domain and is also capable of forming homo-dimers. Both leucine zippers are disordered before binding each other, but, upon binding, both chains become ordered forming a left-handed, four helix-bundle [17]. The resulting hetero-dimer (which is the functional species) binds DNA, and modulates gene expression, transcriptional activation, and apoptosis [16, 18]. Deregulation of c-Myc is mostly associated with aggressive tumors in breast, lung, cervix, and hematopoietic organs [19], as well as with deregulation of genes controlled by RNA polymerases [20].

This system was the first example, showing that an IDP could be targeted with small molecules or peptides. There are two possible approaches to accomplish the targeting: first, designing small molecules that impede the heterodimerization; second, identifying molecules or peptides hampering the binding of the formed hetero-dimer to DNA

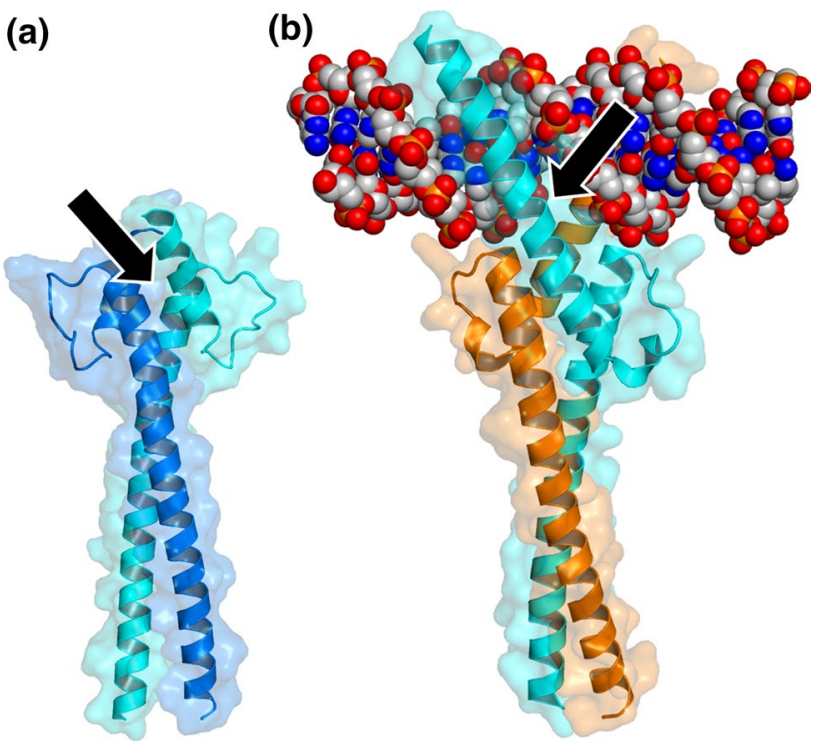

Fig. 2 Structure of the homodimer of Max (PDB entry: 5I4Z) [104] (a) and the heterodimer with c-Myc and DNA [17] (PDB number: $1 \mathrm{NKP}$ ) (b). The arrow in a indicates the homodimer interface; and that in $\mathbf{b}$ indicates the protein-DNA interface. The figure was produced with PyMOL [105] 
(but not the hetero-dimer formation). There have been two attempts of using the former approach and one using the latter, which are described in the next paragraphs.

Inhibitors of c-Myc/Max association have been first found using high-throughput screening of small molecules or peptide-mimetic libraries, based on the application of fluorescence resonance energy transfer (FRET) of fluorescent derivatives of c-Myc and Max [21, 22] together with twoyeast hybrid (TYH) techniques [23]. Then, at a later stage, other biophysical techniques such as circular dichroism (CD) and NMR have been used to assess the binding in vitro [20, 24]. Several compounds have been found to bind simultaneously and independently to different hydrophobic regions of the c-Myc monomer [25] shifting the on-going equilibria among its disordered conformations. The molecule blocks a particular conformation of c-Myc, and this conformation is incapable of interacting with Max [24, 26, 27], and hence, it cannot carry out its related biological functions. That is, there is a shift in the population of conformers populated

Fig. 3 Structure of compounds used in targeting IDPs: a sAJM589 for the c-Myc system; b MSI-1436 for C-PTIB; c NSC635437 for the EW-FLI1 fusion protein; $\mathbf{d}$ the compound targeting p27-KID; e TFP (left side) and Fluphenazine hydrochloride (right side) identified for NUPR1; $f$ the ZZW-115 compound obtained by ligandbased design (a)

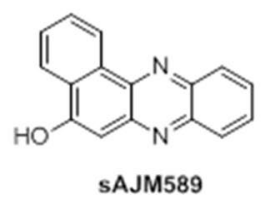<smiles>O=C(COC1(O)C(=O)Nc2c(Cl)ccc(Cl)c21)c1ccc(Cl)cc1</smiles>

NSC635437<smiles>CN1CCN(CCCN2c3ccccc3Sc3ccc(C(F)(F)F)cc32)CC1</smiles>

(f) by the IDP, and therefore, the heterodimer formation is not hampered by direct interaction of the compound with the hetero-dimeric interface (indicated by an arrow in Fig. 2a) but rather by an increase in the population of the monomer, which has a non-competent conformation to form the dimer. However, although the binding of the small molecules induces local structural changes in the protein, mainly around hydrophobic patches, it leaves the rest of the polypeptide chain disordered (that is, the overall disorder through the protein chain is maintained). These local structures are different to the well-folded bundle spanned by the protein when it is bound to Max. $\mathrm{IC}_{50}$ of sAJM589, the best-discovered compound, was $1 \mu \mathrm{M}$ [28] (Fig. 3a).

In the second attempt, fluorescence polarization screenings of c-Myc have allowed the identification of two compounds, which prevent DNA binding and transcription of the heterodimer. Therefore, in this case, the function of the hetero-complex, and not its formation, is directly abolished. However, the molecules lack specificity, as they block the<smiles>CCCCC(CCC(C)[C@H]1CCC2C3C(O)CC4C[C@H](NCCCNCCCCNCCCN)CC[C@]4(C)[C@H]3CC[C@]21C)OS(=O)(=O)O</smiles>

(c)<smiles>CCn1c(C)c(C)n2c3c(=O)n(C)c(=O)n(C)c3nc12</smiles>

(e) (d)

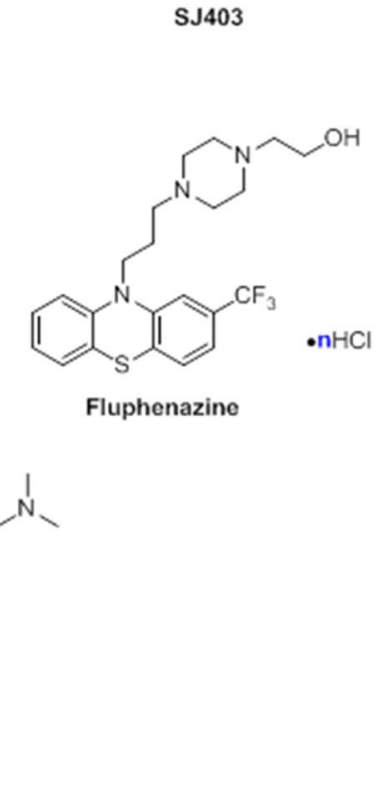


DNA binding of Max homodimer as well [29]; although there are not structural details reported, binding of the compound should occur at the protein-DNA interface (Fig. 2b).

The third attempt of targeting c-Myc also uses the second approach described above (Fig. 1). A variant of the helix-loop-helix domain of c-Myc was designed, containing four mutations in the leucine zipper region. Therefore, the molecule is a variant of the wild-type peptide. This mutant (achieved through chromosomal insertion of a doxycyclineinducible gene) was capable of forming dimers with c-Myc and Max proteins, competing with all the heterodimers of the c-Myc family for their target promoter; therefore, the peptide hampers the function of the dimer, and it could be considered a transgenic tool to inhibit c-Myc in vitro [30, 31]. Although there are not structural details reported, it is tempting to suggest that the heterodimers formed by the mutant peptide do not have the same conformation as the wild-type dimer in the protein-DNA interface (Fig. 2b). Recently, it has been shown that this peptide is capable of penetrating the cells, reverting the expression of c-Mycrelated gene signatures, and shifting equilibria where c-Myc is involved throughout the genome [32]. Taken together, the results suggest that the peptide is very specific and the basis of its function is the DNA binding.

To summarize, the disordered protein c-Myc can be targeted by small molecules, that bind to hydrophobic regions of the isolated polypeptide, leaving its structure mainly disordered. These molecules are capable of hampering heterodimer formation.

\section{The disordered C-terminal region of PTP1B (C-PTP1B): allosterism in regulation of the function of an ID region}

The protein tyrosine phosphatase 1B (PT1B) is overexpressed in breast tumors together with HER2 [33]. Its disordered non-catalytic C-terminal region (C-PT1B) has a regulatory function [34]. The use of a natural product (trodusquemine, MSI-1436) inhibits the metabolic function of PT1B, by binding to its catalytic site [35]. However, MSI1436 (Fig. 3b) is also a non-competitive inhibitor of PTP1B, which binds to C-PTP1B, inducing conformational changes [36]. Although C-PTP1B is mainly disordered, it has a propensity to populate helical conformations around two distinct regions. In fact, several biophysical techniques [FRET, small angle X-ray scattering (SAXS), size exclusion chromatography (SEC), and state-of-the-art NMR] have been used to elucidate the flickering helical structure in C-PTP1B and how it changes in the presence of MSI-1436. The compound binds to residues of the second, flickering helical region of C-PTP1B (which is slightly more hydrophobic than the other helical patch), and to another additional site close to the catalytic domain. Binding to C-PTP1B induces allosteric changes in the protein, locking the whole protein in an inactive state. At this stage, although C-PTP1B in complex with the compound has a more compact hydrodynamic radius than that of the isolated protein [36], it is not known whether the complex formed has a fuzzy conformation, remaining disordered as it happens with the c-Myc/Max complex and the assayed molecules. In addition, MSI-1436 disrupts HER2 signaling and inhibits tumorigenesis in xenografted mice, showing that PTP1B is, as well, a valid target to treat breast cancer [36].

Therefore, in this example, the targeting of the disordered protein with small molecules does not hamper directly the interaction with other proteins (as in the case of c-Myc/ Max system), but rather induces allosteric conformational changes, which impedes subsequent binding (and its biological function).

\section{The EWS-FLI1 fusion protein: designing small compounds or peptides to hamper PPIs of an IDP}

There are some leukemia and sarcomas that carry non-random chromosomal translocations, encoding novel fusion TFs. These TFs are produced under cellular stress conditions, and are essential to initiate and maintain the molecular pathogenesis of the cancer. Although the majority of these fusion proteins are TFs, some of them are also involved in phosphorylation processes. The genomic fusion of TET family members, such as Ewing's sarcoma oncoprotein (EWS), usually involves an ets gene (erythroblastosis virus E26 transforming sequence gene) such as the FLII [37]. This fusion yields the Ewing's family of oncogenic proteins (EWS-fusion proteins or EFPs). The N-terminal region of the EFP belongs to the EWS, which contains the transcriptional activation domain (TA); and the C-terminal region comes from the fusion partner, containing the DNA-binding promoter specificity, which determines tumor phenotype. The function of the TA is conferred by the presence of multiple tyrosines at different polypeptide sites.

Biophysical and computational studies have shown that EWS-FLI1 is an IDP [38, 39]. The binding of the fusion EWS-FLI1 protein to RNA helicase is essential in tumor maintenance in Ewing's sarcoma family tumors [37]; the binding region of the RNA helicase involves residues 647-1075, and that polypeptide patch is not used in binding to other biomolecules. A compound screening using surface plasmon resonance (SPR) allowed the identification of a compound, NSC635437 (Fig. 3c), which binds to EWS-FLI1 [40]. No clues have been provided about the possible local structure acquired by EFP upon binding to the molecule, but computational studies suggest that binding to any compound leaves EWS-FLI1 disordered [37], forming fuzzy complexes (as with the c-Myc/Max example). Although structural details of the EFP binding region to the drug are lacking, as 
well as any other structural details on other protein regions, it is tempting to suggest (based on mutational studies on natural partners [37]) that some tyrosines along the sequence are involved in the binding (and hydrophobic interactions). An improved molecule developed starting from NSC635437 has led to [40]: (1) disruption of the interaction between the RNA helicase and EWS-FLI1; (2) apoptosis of cancerous cells; and (3) decrease of tumor volume in Ewing's sarcoma xenografted mice.

The same research group has also found a peptide [40], comprising residues 823-832 from RNA helicase that is capable of blocking the binding between EWS-FLI1 and the intact RNA helicase, suggesting that NSC635437 and the peptide bind to the same fusion protein site (although allosteric processes cannot be fully excluded). However, no clues have been provided whether the bound RNA-helicase-derived peptide leaves EWS-FLI1 disordered (that is, whether a fuzzy complex is formed). Therefore, the authors have used both approaches outlined above (either design of a peptide mimicking the binding region of one of the proteins or screening of a compound library, Fig. 1) to inhibit PPIs between the fusion protein and the helicase.

Therefore, in this example, hydrophobic interactions (involving Tyr residues) are also important in the design of the peptide or the molecules hampering the PPIs of the fusion protein.

\section{The AF4-AF9 protein system: another complex formed in fusion proteins}

Translocations involving the Mixed Lineage Leukemia $(M L L)$ gene are involved in leukemogenesis characterized by poor prognosis [41]: fusion of TFs to MLL products is thought to be one of the triggering mechanisms of leukemia [42]. Among the several MLL fusion partners, AF4 and AF9 proteins are quite common. AF9 is a component of biochemically isolated complexes with functions in transcriptional elongation such as the AEP complex, which, in turn, contains the AF4 protein [43]. Both proteins form complexes, either when belonging to the chimeric MLL protein or in their native isolated states [44]. In fact, disruption of the AF4-AF9 complex results in necrotic cell death in cell lines harboring MLL translocations [45], which indicates the importance of the complex formation and its use as possible pharmaceutical target against leukemia.

AF9 and AF4 are IDPs when isolated in solution and the interacting region of AF4 has been previously identified using TYH techniques [46]. When AF9 binds to a peptide containing the recognition region of AF4 (comprising residues 760-773), it folds (acquiring a conformation with three $\alpha$-helices and a two-stranded $\beta$-sheet, packed on one of the helices), although it maintains a high flexibility [47]. The AF4-derived peptide also folds acquiring several turns of $\alpha$-helix (Fig. 4); therefore, in this system, the binding of both proteins induces their folding. The interface between both polypeptides is hydrophobic, with several residues of the peptide buried in the hydrophobic core of AF9. This AF4-derived peptide is capable of disrupting the AF4-AF9 complex both in vitro and in vivo, inhibiting the proliferation of leukemia cells (via apoptosis) with chromosomal translocation expressing MLL-AF4 fusion genes [44]. In addition, the peptide did not alter the proliferative capacity of hematopoietic progenitor cells.

Therefore, in this example, knowledge of the PPI interfaces of both proteins-corresponding to the application of the first approach described above-allows the identification of an inhibitor, as it occurs with the c-Myc/Max one. However, conversely to that system, the inhibitor-peptide/ AF9 complex yields two well-folded polypeptide chains, although AF9 keeps a high flexibility. Furthermore, the regions involved in binding in both polypeptide chains have a large number of implicated hydrophobic residues [as it happens in the c-Myc/Max system and in the EWS-FLI1 one].

Fig. 4 Structure of the complex between the AF9 and the peptide-derived AF4 polypeptide. Ensemble of structures of the bound peptide (left), and details of a single peptide structure in a rotated view of the protein (right). The figure was produced with PyMOL [105] from the PDB entry 2LM0 [47]
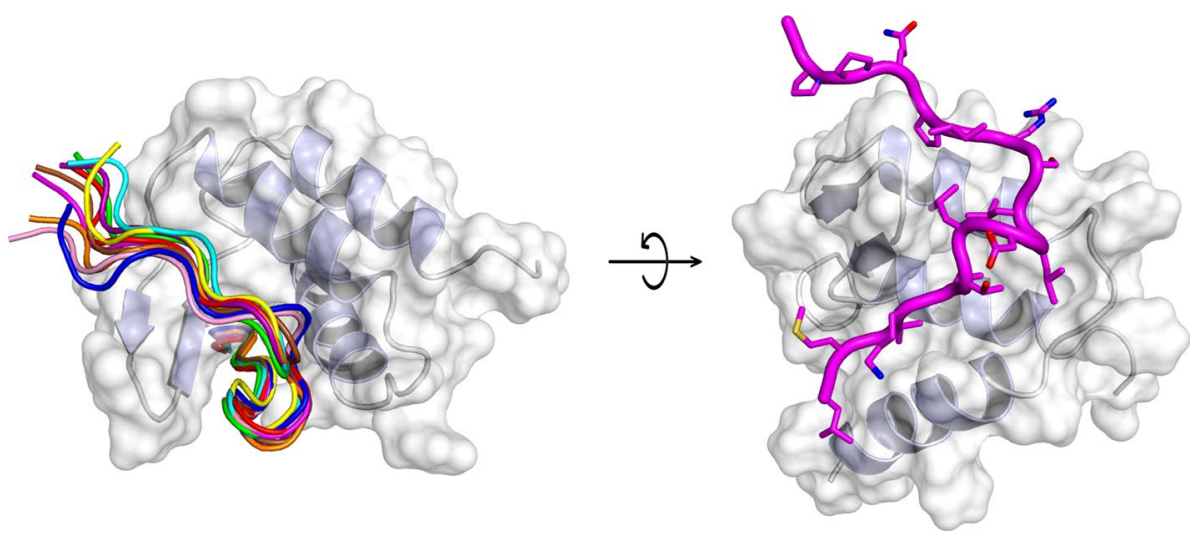


\section{The p27 system: drug targeting of an IDP using screening of fragment libraries}

p27Kip1 (or p27, kinase inhibitory protein 1, and also known as CDKN1B) is a modulator of cyclic-dependent kinases (cdk), that controls eukaryotic cell division [48, 49]. The $\mathrm{N}$ terminus of the protein contains the kinase inhibitory domain of p27 (p27-KID, residues 28-90 in p27); this domain binds to, and therefore, modulates (by phosphorylation of its tyrosines) the activity of $\mathrm{Cdk} 2 /$ cyclin complexes. This regulation is incorrectly activated in chronic myelogenous leukemia and breast cancer [50, 51]. In addition, phosphorylation of this domain at a threonine is related to increased metastatic processes and cell migration $[52,53]$. The p27-KID is an IDP [54, 55].

It has been hypothesized that, if a small molecule could bind to $\mathrm{p} 27-\mathrm{KID}$, this could induce a conformational change in the disordered polypeptide chain, which would yield an incompetent species incapable of binding to the Cdk2/cyclin complexes (in a similar reasoning to that used for the c-Myc/ Max system) [55]. Using NMR for screening a fragment compound library, nine molecules are capable of blocking the $\mathrm{p} 27-\mathrm{KIP} / \mathrm{Cdk} 2 /$ cyclin complex formation, with their interactions with the IDP being described at atomic level. These compounds could be classified in two groups, each of which binds to different regions of p27-KID. The region of p27-KID involved in the binding has a large amount of hydrophobic residues [as it occurs in the EWS-FLI1 system; the AF4-AF9 one; and the c-Myc/Max complex]. The binding of the small-molecular inhibitors hampers the ability of p27 to sequester the Cdk2/cyclin complex, restoring partially the Cdk2/cyclin activity. Although p27-KID remains disordered upon binding to the small molecules, the binding induces a shift in the conformational equilibria of the IDP [54], as judged by NMR relaxation measurements of the complex with one of the compounds, again in analogy with the behavior of the c-Myc/Max system.

It must be pinpointed that for this system, a peptide resembling the Cdk2/cyclin interface involved in binding to p27-KID has not been used as an inhibitor of the interactions between the two proteins, but a small organic inhibitor. We think that it should be interesting to explore the possibility of finding a peptide capable of binding the same PPI interface as the screened fragments, which could induce folding of the p27-KIP, and mimicking the polypeptide region of the Cdk2/cyclin complex.

To sum up, in this case, a library was screened to identify the compounds targeting the PPI interface of p27-KID (as it happens with c-Myc/Max system). The molecules bind to the hydrophobic regions of the protein (as other examples described before). In addition, the protein does not acquire a folded conformation upon binding to any of the small molecules (as it has been described in other systems).
The p53 system: a master regulator of cell functions with ID regions

The protein p53 is a TF and a master regulator of cellular function, modulating the expression of genes involved in senescence, cell cycle arrest, and apoptosis [56, 57]. The inactivation of p53 results from the overexpression of proteins such as E3 ubiquitin ligases that can down-regulate the function of wild-type p53 through its degradation [58]. Indeed, in un-stressed cells, p53 levels are low due to this rapid ubiquitination and degradation. One of such E3 ligases is MDM2 (murine double minute 2). MDM2 also promotes its own degradation [59]: under cellular stress, MDM2 phosphorylates at specific locations and it is degraded, triggering p53 stabilization [60]. In addition, under similar stress conditions, MDM2 binds p53 and prevents its interaction with the general transcription machinery. The complex between MDM2 and p53 is largely formed by the interaction between the N-terminal domain of MDM2 (residues 1-124) and the $\mathrm{N}$-terminal TA of p53 (residues 1-61, p53-TA). There is a competition for binding to p53-TA, among the $\mathrm{N}$ terminus of MDM2 and other co-activators involved in up-regulation of transcription [61]. Under stress conditions, p53-TA undergoes extensive phosphorylation-whose extent depends on the stress situation-hampering the binding to MDM2, and enhancing the binding to other co-activators.

In the absence of MDM2, the isolated p53-TA is disordered, with a hydrodynamic radius similar to that of chemically unfolded proteins of the same size, but forming flickering, local elements of secondary structure as judged by the use of several biophysical techniques [62-65]; MDM2 also undergoes a compaction upon binding to p53 [66], but it is well folded in isolation. There are several NMR and crystals structures of the $\mathrm{N}$-terminal domain of MDM2 in complex with peptides derived from p53 or with other molecules [67-69]. In all of those structures (the first one reported in 1996 describes the binding between the $\mathrm{N}$ terminal region of MDM2 and a p53-TA-derived peptide [68]), the p53-TA peptide adopts an $\alpha$-helical conformation. In that folding topology, hydrophobic residues Phe19, Trp23, and Leu26 of the p53-TA (Fig. 5), which are part of the amphipathic helix, are inserted into a hydrophobic pocket on the MDM2 surface. This structure has been used as a starting point to develop inhibitory compounds applying the two approaches used for targeting IDPs: (1) the design of a peptide or peptide mimetic with the features of the p53-TA region; and (2) screening of libraries of compounds that could fit into the hydrophobic groove of MDM2. Both approaches have allowed the screening, design, synthesis and testing (using fluorescence, CD, NMR, and SPR) of several dozens of small inhibitors of this PPI interface [70-72], and even the design of peptides and peptide mimetics which have an affinity similar to that of both intact protein partners [73]. 


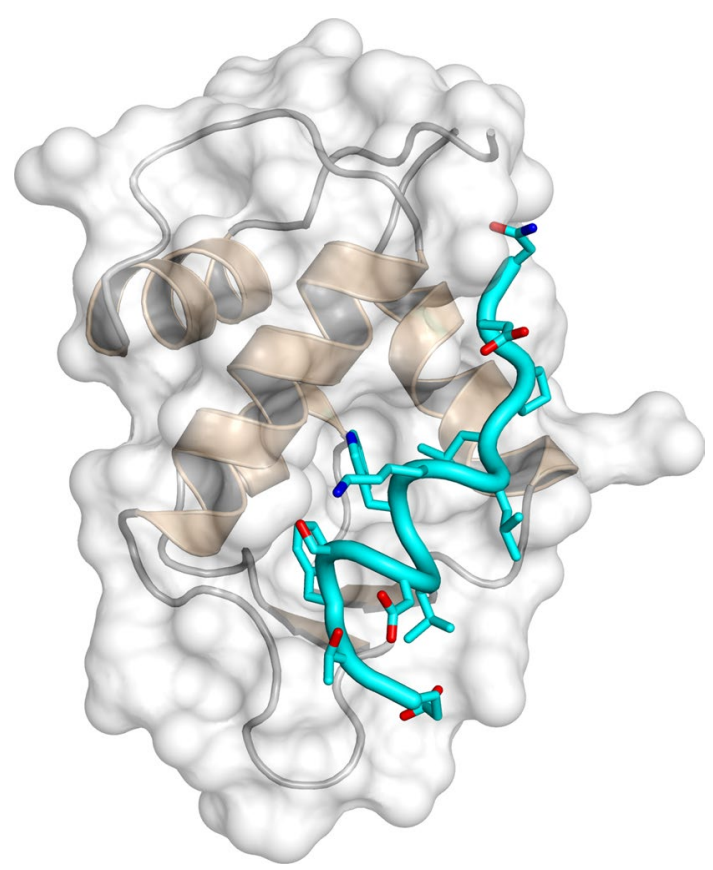

Fig. 5 Structure of the complex between the MDM2 and p53-derived peptide from TA region. The figure was produced with PyMOL [105] from the PDB entry 1YCR [68]

Then, to sum up, this example is a case of folding-uponbinding of a particular ID polypeptide patch (similarly to what happens in the AF4-AF9 system), and, again, hydrophobic residues intervene in the recognition region.

\section{The NUPR1 system: an essential protein for cancer development}

NUPR1 was first described as being activated during the acute phase of pancreatitis [74]. Afterwards, the inducible expression of NUPR1 was discovered to occur under stress conditions caused by many stimuli, in most cell types, and therefore, NUPR 1 can be considered a stress-associated protein $[75,76]$. Then, NUPR1 was found to be over-expressed in many cancer tissues. At the cellular level, NUPR1 was involved in cancer-associated processes including cellcycle regulation, apoptosis [77, 78], senescence [79], cell migration and invasion [80], and metastases [81]. Indeed, NUPR1 has attracted attention due to its role in promoting cancer development and progression in the pancreas [82, 83], as NUPR1-dependent effects also mediate resistance to anticancer drugs [84-86]. Remarkably, we have showed that genetic inactivation of NUPR 1 antagonizes the growth of pancreatic adenocarcinoma (PDAC) [80, 87], and other laboratories have shown that genetic inactivation of NUPR1 stops the growth of hepatocarcinoma [88], non-small lung cancer [89], cholangiocarcinoma [90], glioblastoma [91], multiple myeloma [92, 93], and osteosarcoma [94]. These findings indicate that NUPR 1 is a hub protein involved in several key signaling routes, and it could be considered a promising therapeutic target for the development of new anti-cancer therapies.

Structurally, NUPR1 is an 82-residue-long, monomeric, basic IDP [95-99]. It has two hot spot regions (identified by in silico procedures and protein engineering studies [98]) involved in binding to its natural partners (DNA, prothymosin $\alpha$, male-specific lethal protein, and the C-terminal domain of RING1B): (1) the 30's region, where the two tyrosine residues of the protein are located; and (2) the region around Thr68. Both regions are among the most hydrophobic polypeptide patches in the chain $[96,98,99]$. However, in all the complexes, NUPR1 remains disordered.

We have developed a combination of biophysical, biochemical, bioinformatic [molecular dynamics (MD) simulations], and biological approaches for a molecular screening in vitro, in vivo, in silico, and in cellulo to select potential drug candidates against NUPR1 [100]. In the first step, we have repurposed a well-known drug; and in a second step, we have: (1) improved its efficacy and efficiency; and (2) decreased its side effects. In our approach, we have used the second strategy employed in drug-targeting IDPs (Fig. 1): screening of a commercial library (Prestwick Chemical Library, http://www.prestwickchemical.com/libraries-scree ning-lib-pcl.html) to identify a lead compound. The screening has been carried out with fluorescence-thermal denaturation. We have selected those compounds with larger variations either in the thermal denaturation midpoints or in the denaturation profiles, and next, we have measured their affinity for NUPR1 using isothermal titration calorimetry (ITC). We have chosen those with the most favourable affinities, with values similar to those found for the NUPR 1 natural $[78,96,98]$ or non-natural [99] binding partners. We then have combined SAR (structure-activity relationships) by NMR results and MD simulations, carried out independently of each other, to verify that a similar set of residues were affected by the binding of the compound. The most promising compounds identified have been trifluoperazine (TFP) and its structurally related fluphenazine hydrochloride (Fig. 3e). Both compounds bind to both hot spots of NUPR1, which remains disordered upon binding, adopting particular local conformations (as it happened in the c-Myc/Max system) (Fig. 6). Cell viability assays with TFP have led to an $\mathrm{IC}_{50} \sim 10 \mu \mathrm{M}$. Most importantly, tests of TFP in vivo, with human pancreatic cancer cell-derived xenografts implanted into immune-compromised mice, have shown an arrest of the tumor growth in a dose-dependent manner [100]. Unfortunately, high doses of TFP, as that used for PDAC treatment, have also led to neurological side effects, such as strong lethargy and hunched posture, which preclude TFP use in clinics to treat cancers. 


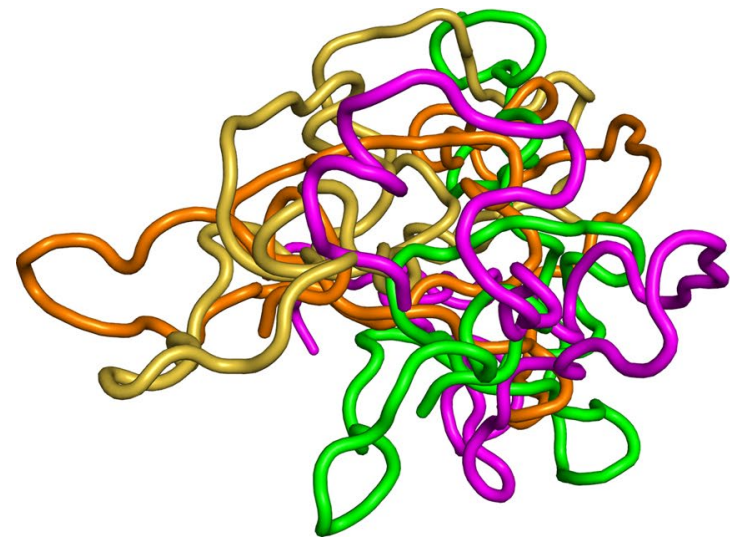

Fig. 6 Simulated structures of NUPR1 in the first encounter with the compound ZZW-115. Examples of conformations in the solution ensemble of NUPR1 (left), and details of the binding pocket for

In a second step, we have used a rational, in silico ligandbased design relying on a combination of MD and docking, which guided the organic synthesis of TFP-derived compounds. As expected from the in silico studies, the synthesized compounds have shown a stronger affinity in vitro for NUPR1, as indicated by CD, fluorescence, ITC and NMR. The best compound (that with the largest affinity for NUPR1, and within the same order than that of NUPR1 for its natural partners), ZZW-115 (Fig. 5f), kills different kinds of cancer cells with $\mathrm{IC}_{50}$ values ranging from 0.84 to $4.93 \mu \mathrm{M}$ [101]. Most importantly, ZZW-115 shows a dose-dependent tumor regression in xenografted mice, almost leading to tumor disappearance after 30 days of treatment with $5 \mathrm{mg} /(\mathrm{kg}$ day), with no apparent neurological effects. At the cellular level, ZZW-115 induces cell death by both necroptotic [as measured by lactate dehydrogenase (LDH) release] and apoptotic (as measured by caspase 3/7 activity) mechanisms, with a concomitant mitochondrial metabolism failure that triggers lower production of ATP and reactive oxygen species (ROS) overproduction [101]. Importantly, these molecular mechanisms are similar to those observed in NUPR1-deficient cells [102] and can be inhibited by Necrostatin-1 (an inhibitor of necroptosis) and Z-VAD-FMK (an inhibitor of caspases). We have also proved that ZZW-115 still exerts its effect by binding to NUPR1, although we could not prove that NUPR 1 is the sole protein targeted. In fact, the antitumor effect of ZZW-115 is not influenced by the resistance to others drugs in PDAC treatment, and this compound might modulate another intracellular pathways, by binding also to other macromolecules.

Since NUPR1 is over-expressed in several tumors, we have also evaluated the effect of treating cellular lines derived from those tumors with ZZW-115. Cells such as U87 (glioblastoma), A375 and B16 (melanoma), U2OS and SaOS-2 (osteosarcoma), HT29, SK-CO-1 and LS174T

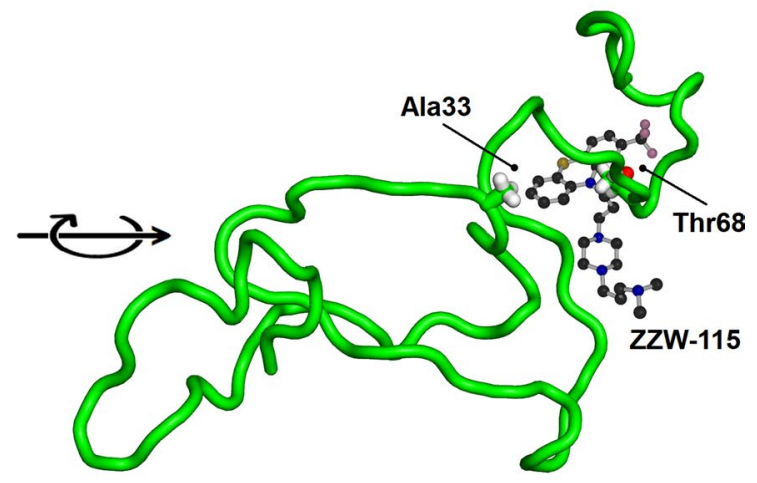

ZZW-115 (right). The figure was produced with PyMOL [105] from simulation models previously obtained $[97,100]$

(colon cancer), H1299 and H358 (lung cancer), HepG2 (hepatocarcinoma), PC-3 (prostate), THP-1 (acute monocytic leukemia), Daudi (lymphoma), Jurkat (acute T-cell leukemia), and MDA-MB-231 (breast cancer) have been treated with ZZW-115. The compound is efficient in killing those cells with $\mathrm{IC}_{50}$ values ranging from 0.42 to $7.75 \mu \mathrm{M}$ [101]. These data indicate that ZZW-115 could be an anticancer molecule active in several tissues.

Therefore, ZZW-115 constitutes a promising drug candidate for PDAC with a new molecular mechanism, since it combines the concomitant induction of necroptosis and apoptosis. The compound, obtained by rational ligand-based design, binds to the hydrophobic regions of NUPR 1 as in other IDPs and forms a fuzzy complex with the protein.

\section{Conclusions}

Our work and examples from other laboratories indicate that targeting of IDPs is feasible (even in proteins not involved in cancer development [103]). In all cases described so far, the molecules work by hampering the DNA-protein or protein-protein interactions in which the IDP is implicated. The binding of the designed compounds in IDPs mainly involves, as it happens with well-folded proteins, protein hydrophobic regions. Interestingly enough, in most of the targeted IDPs, binding of the molecules does not induce a folding of the polypeptide chain of the disordered protein; in fact, proteinfolding-upon-binding only occurs when the molecule is a peptide [as in the AF4-AF9 system or in the MDM2-p53 complex]. It should be interesting to elucidate whether this is a particular feature of the corresponding IDP, or alternatively it is due to the fact that the smaller size of a molecule (compared to that of a peptide) hampers the protein in acquiring a well-folded conformation, but influences enough 
to shift the conformational equilibrium of the protein and then obstructing its function. Thus, folding-upon-binding might require the cooperative target of several, appropriately distributed interaction hot spots.

The fact that either screening of libraries or dissection and study of PPIs in the formed complexes of IDPs with other biomolecules can be used in targeting IDPs indicates that the drug-design techniques employed in well-folded proteins can be used in IDPs, with slight variations. Moreover, the designed compounds against IDPs encompass, as in wellfolded proteins, either small, synthetic organic molecules, or peptides (and their derivatives). Differences among the examples described rely on how molecular design is carried out against IDPs, since this design is essentially ligandbased, as opposed to structure-based in well-folded proteins. This is due to the fact that there is not a single structure for the corresponding IDP. However, the design of drugs targeting IDPs is still in its infancy, and additional examples are expected to shed light on details in common among successful attainments, as well as novel ways for pursuing further rational drug design strategies.

Funding This work was supported by La Ligue Contre le Cancer, INCa, Canceropole PACA and INSERM] to JLI; Miguel Servet Program from Instituto de Salud Carlos III under grant CPII13/00017 to OA; Fondo de Investigaciones Sanitarias under Grants PI15/00663 and PI18/00343 to OA; Spanish Ministry of Economy and Competitiveness, with FEDER funds, under grants BFU2016-78232-P to AVC, RTI2018-097991-BI00 to JLN; Diputación General de Aragón under Grants Protein Targets and Bioactive Compound Group to AVC, and Digestive Pathology Group to OA; Centro de Investigación Biomédica en Red en Enfermedades Hepáticas y Digestivas (CIBERehd) to OA and AVC; Programme CAI YUANPEI to YX and JLI; and National Natural Science Foundation of China (81502920) to YX. The Fondation de France supported PSC.

\section{Compliance with ethical standards}

Conflict of interest The authors have filed a patent entitled "NUPR1 inhibition for treating cancer" (European Patent Application PCT/ EP2019/064184).

Open Access This article is distributed under the terms of the Creative Commons Attribution 4.0 International License (http://creativeco mmons.org/licenses/by/4.0/), which permits unrestricted use, distribution, and reproduction in any medium, provided you give appropriate credit to the original author(s) and the source, provide a link to the Creative Commons license, and indicate if changes were made.

\section{References}

1. Tompa P (2011) Unstructural biology coming of age. Curr Opin Struct Biol 21:419-425

2. Uversky VN (2011) Intrinsically disordered proteins from A to Z. Int J Biochem Cell Biol 43:1090-1103
3. Oates ME, Romero P, Ishida T, Ghalwash M, Mizianty MJ, Xue B, Dosztanyi Z, Uversky VN, Obradovic Z, Kurgan L et al (2013) $\mathrm{D}(2) \mathrm{P}(2)$ : database of disordered protein predictions. Nucl Acids Res 41:D508-516

4. Metallo SJ (2010) Intrinsically disordered proteins are potential drug targets. Curr Opin Chem Biol 14:481-488

5. Iakoucheva LM, Brown CJ, Lawson JD, Obradovic Z, Dunker AK (2002) Intrinsic disorder in cell-signaling and cancerassociated proteins. J Mol Biol 323:573-584

6. Uversky VN, Oldfield CJ, Dunker AK (2008) Intrinsically disordered proteins in human diseases: introducing the D2 concept. Ann Rev Biophys 37:215-246

7. Tompa P, Szasz C, Buday L (2005) Structural disorder throws new light on moonlighting. Trends Biochem Sci 30:484-489

8. Liu Z, Huang Y (2014) Advantages of proteins being disordered. Protein Sci 23:539-550

9. Wright PE, Dyson HJ (2015) Intrinsically disordered proteins in cellular signalling and regulation. Nat Rev Mol Cell Biol 16:18-29

10. Cheng Y, LeGall T, Oldfield CJ, Mueller JP, Van YY, Romero P, Cortese MS, Uversky VN, Dunker AK (2006) Rational drug design via intrinsically disordered protein. Trends Biotechnol 24:435-442

11. Hughes JP, Rees S, Kalindjian SB, Philpott KL (2011) Principles of early drug discovery. Br J Pharmacol 162:1239-1249

12. Cano CE, Iovanna JL (2010) Stress proteins and pancreatic cancer metastasis. Sci World J 10:1958-1966

13. Calderwood SK, Khaleque MA, Sawyer DB, Ciocca DR (2006) Heat shock proteins in cancer: chaperones of tumorigenesis. Trends Biochem Sci 31:164-172

14. Jego G, Hazoume A, Seigneuric R, Garrido C (2013) Targeting heat shock proteins in cancer. Cancer Lett 332:275-285

15. Dang CV (1999) c-Myc target genes involved in cell growth, apoptosis, and metabolism. Mol Cell Biol 19:1-11

16. Ponzielli R, Katz S, Barsyte-Lovejoy D, Penn LZ (2005) Cancer therapeutics: targeting the dark side of Myc. Eur J Cancer 41:2485-2501

17. Nair SK, Burley SK (2003) X-ray structures of Myc-Max and Mad-Max recognizing DNA. Molecular bases of regulation by proto-oncogenic transcription factors. Cell 112:193-205

18. Amati B (2001) Integrating Myc and TGF-beta signalling in cell-cycle control. Nat Cell Biol 3:E112-E113

19. Soucek L, Whitfield J, Martins CP, Finch AJ, Murphy DJ, Sodir NM, Karnezis AN, Swigart LB, Nasi S, Evan GI (2008) Modelling Myc inhibition as a cancer therapy. Nature 455:679-683

20. Grandori C, Gómez-Román N, Felton-Edkins ZA, Ngouenet C, Galloway DA, Eisenman RN, White RJ (2005) c-Myc binds to human ribosomal DNA and stimulates transcription of rRNA genes by RNA polymerase I. Nat Cell Biol 7:311-318

21. Berg T, Cohen SB, Desharnais J, Sonderegger C, Maslyar DJ, Goldberg J, Boger DL, Vogt PK (2002) Small-molecule antagonists of Myc/Max dimerization inhibit Myc-induced transformation of chicken embryo fibroblasts. Proc Natl Acad Sci USA 99:3830-3835

22. Xu Y, Shi J, Yamamoto N, Moss JA, Vogt PK, Janda KD (2006) A credit-card library approach for disrupting protein-protein interactions. Bioorg Med Chem 14:2660-2673

23. Yin X, Giap C, Lazo JS, Prochownik EV (2003) Low molecular weight inhibitors of Myc-Max interaction and function. Oncogene 22:6151-6159

24. Follis AV, Hammoudeh DI, Wang H, Prochownik EV, Metallo SJ (2008) Structural rationale for the coupled binding and unfolding of the c-Myc oncoprotein by small molecules. Chem Biol 15:1149-1155

25. Hammoudeh DI, Follis AV, Prochownik EV, Metallo SJ (2009) Multiple independent binding sites for small-molecule 
inhibitors on the oncoprotein c-Myc. J Am Chem Soc 131:7390-7401

26. Follis AV, Hammoudeh DI, Daab AT, Metallo SJ (2009) Smallmolecule perturbation of competing interactions between c-Myc and Max. Bioorg Med Chem Lett 19:807-810

27. Mustata G, Follis AV, Hammoudeh DI, Metallo SJ, Wang H, Prochownik EV, Lazo JS, Bahar I (2009) Discovery of novel Myc-Max heterodimer disruptors with a three-dimensional pharmacophore model. J Med Chem 52:1247-1250

28. Choi SH, Mahankali M, Lee SJ, Hull M, Petrassi HM, Chatterjee AK, Schultz PG, Jones KA, Shen W (2017) Targeted disruption of Myc-Max oncoprotein complex by a small molecule. ACS Chem Biol 12:2715-2719

29. Kiessling A, Sperl B, Hollis A, Eick D, Berg T (2006) Selective inhibition of c-Myc/Max dimerization and DNA binding by small molecules. Chem Biol 13:745-751

30. Soucek L, Helmer-Citterich M, Sacco A, Jucker R, Cesareni G, Nasi S (1998) Design and properties of a Myc derivative that efficiently homodimerizes. Oncogene 17:2463-2472

31. Soucek L, Jucker R, Panacchia L, Ricordy R, Tatò F, Nasi S (2002) Omomyc, a potential Myc dominant negative, enhances Myc-induced apoptosis. Cancer Res 62:3507-3510

32. Beaulieu ME, Jauset T, Massó-Vallés D, Martínez-Martín S, Rahl P, Maltais L, Zacarias-Fluck MF, Casacuberta-Serra S, Serrano Del Pozo E, Fiore C et al (2019) Intrinsic cell-penetrating activity propels Omomyc from proof of concept to viable anti-MYC therapy. Sci Transl Med. https://doi.org/10.1126/ scitranslmed.aar5012

33. Julien SG, Dube N, Read M, Penney J, Paquet M, Han Y, Kennedy BP, Muller WJ, Tremblay ML (2007) Protein tyrosine phosphatase 1B deficiency or inhibition delays ErbB2-induced mammary tumorigenesis and protects from lung metastasis. Nat Gen 39:338-346

34. Hao L, Tiganis T, Tonks NK, Charbonneau H (1997) The noncatalytic $\mathrm{C}$-terminal segment of the $\mathrm{T}$ cell protein tyrosine phosphatase regulates activity via an intramolecular mechanism. J Biol Chem 272:29322-29329

35. Lantz KA, Hart SG, Planey SL, Roitman MF, Ruiz-White IA, Wolfe HR, McLane MP (2010) Inhibition of PTP1B by trodusquemine (MSI-1436) causes fat-specific weight loss in diet-induced obese mice. Obesity 18:1516-1523

36. Krishnan N, Koveal D, Miller DH, Xue B, Akshinthala SD, Kragelj J, Jensen MR, Gauss CM, Page R, Blackledge M et al (2014) Targeting the disordered C terminus of PTP1B with an allosteric inhibitor. Nat Chem Biol 10:558-566

37. Lee KA (2012) Molecular recognition by the EWS transcriptional activation domain. Adv Exp Med Biol 725:106-125

38. Ng KP, Potikyan G, Savene RO, Denny CT, Uversky VN, Lee KA (2007) Multiple aromatic side chains within a disordered structure are critical for transcription and transforming activity of EWS family oncoproteins. Proc Natl Acad Sci USA 104:479-484

39. Uren A, Tcherkasskaya O, Toretsky JA (2004) Recombinant EWS-FLI1 oncoprotein activates transcription. Biochemistry 43:13579-13589

40. Erkizan HV, Kong Y, Merchant M, Schlottmann S, BarberRotenberg JS, Yuan L, Abaan OD, Chou TH, Dakshanamurthy S, Brown ML et al (2009) A small molecule blocking oncogenic protein EWS-FLI1 interaction with RNA helicase A inhibits growth of Ewing's sarcoma. Nat Med 15:750-756

41. Dimartino JF, Cleary ML (1999) MLL rearrangements in haematological malignancies: lessons from clinical and biological studies. Br J Haematol 106:614-626

42. Zeisig BB, Schreiner S, Garcia-Cuellar MP, Slany RK (2003) Transcriptional activation is a key function encoded by MLL fusion partners. Leukemia 17:359-365
43. Yokoyama A, Lin M, Naresh A, Kitabayashi I, Cleary ML (2010) A higher-order complex containing AF4 and ENL family proteins with P-TEFb facilitates oncogenic and physiologic MLLdependent transcription. Cancer Cell 17:198-212

44. Srinivasan RS, Nesbit JB, Marrero L, Erfurth F, LaRussa VF, Hemenway CS (2004) The synthetic peptide PFWT disrupts AF4-AF9 protein complexes and induces apoptosis in $\mathrm{t}(4 ; 11)$ leukemia cells. Leukemia 18:1364-1372

45. Palermo CM, Bennett CA, Winters AC, Hemenway CS (2008) The AF4-mimetic peptide, PFWT, induces necrotic cell death in MV4-11 leukemia cells. Leukemia Res 32:633-642

46. Slany RK, Lavau C, Cleary ML (1998) The oncogenic capacity of HRX-ENL requires the transcriptional transactivation activity of ENL and the DNA binding motifs of HRX. Mol Cell Biol 18:122-129

47. Leach BI, Kuntimaddi A, Schmidt CR, Cierpicki T, Johnson SA, Bushweller JH (2013) Leukemia fusion target AF9 is an intrinsically disordered transcriptional regulator that recruits multiple partners via coupled folding and binding. Structure 21:176-183

48. Sherr CJ, Roberts JM (1999) CDK inhibitors: positive and negative regulators of G1-phase progression. Genes Dev 13:1501-1512

49. Mitrea DM, Kriwacki RW (2013) Regulated unfolding of proteins in signaling. FEBS Lett 587:1081-1088

50. Chu I, Sun J, Arnaout A, Kahn H, Hanna W, Narod S, Sun P, Tan CK, Hengst L, Slingerland J (2007) p27 phosphorylation by Src regulates inhibition of cyclin E-Cdk2. Cell 128:281-294

51. Grimmler M, Wang Y, Mund T, Cilensek Z, Keidel EM, Waddell MB, Jakel H, Kullmann M, Kriwacki RW, Hengst L (2007) Cdkinhibitory activity and stability of p27Kip1 are directly regulated by oncogenic tyrosine kinases. Cell 128:269-280

52. Viglietto G, Motti ML, Bruni P, Melillo RM, D'Alessio A, Califano D, Vinci F, Chiappetta G, Tsichlis P, Bellacosa A et al (2002) Cytoplasmic relocalization and inhibition of the cyclindependent kinase inhibitor p27(Kip1) by PKB/Akt-mediated phosphorylation in breast cancer. Nat Med 8:1136-1144

53. Zhao H, Faltermeier CM, Mendelsohn L, Porter PL, Clurman BE, Roberts JM (2014) Mislocalization of p27 to the cytoplasm of breast cancer cells confers resistance to anti-HER2 targeted therapy. Oncotarget 5:12704-12714

54. Ban D, Iconaru LI, Ramanathan A, Zuo J, Kriwacki RW (2017) A small molecule causes a population shift in the conformational landscape of an intrinsically disordered protein. J Am Chem Soc 139:13692-13700

55. Iconaru LI, Ban D, Bharatham K, Ramanathan A, Zhang W, Shelat AA, Zuo J, Kriwacki RW (2015) Discovery of small molecules that inhibit the disordered protein, p27(Kip1). Sci Rep 5:15686

56. Kastenhuber ER, Lowe SW (2017) Putting p53 in context. Cell 170:1062-1078

57. White E (2016) Autophagy and p53. Cold Spring Harbor Pers Med 6:a026120

58. Vogelstein B, Lane D, Levine AJ (2000) Surfing the p53 network. Nature 408:307-310

59. Fang S, Jensen JP, Ludwig RL, Vousden KH, Weissman AM (2000) Mdm2 is a RING finger-dependent ubiquitin protein ligase for itself and p53. J Biol Chem 275:8945-8951

60. Stommel JM, Wahl GM (2004) Accelerated MDM2 auto-degradation induced by DNA-damage kinases is required for $\mathrm{p} 53$ activation. EMBO J 23:1547-1556

61. Kruse JP, Gu W (2009) Modes of p53 regulation. Cell 137:609-622

62. Chi SW, Lee SH, Kim DH, Ahn MJ, Kim JS, Woo JY, Torizawa T, Kainosho M, Han KH (2005) Structural details on mdm2-p53 interaction. J Biol Chem 280:38795-38802 
63. Huang F, Rajagopalan S, Settanni G, Marsh RJ, Armoogum DA, Nicolaou N, Bain AJ, Lerner E, Haas E, Ying L, Fersht AR (2009) Multiple conformations of full-length p53 detected with single-molecule fluorescence resonance energy transfer. Proc Natl Acad Sci USA 106:20758-20763

64. Vise PD, Baral B, Latos AJ, Daughdrill GW (2005) NMR chemical shift and relaxation measurements provide evidence for the coupled folding and binding of the p53 transactivation domain. Nucl Acids Res 33:2061-2077

65. Wells M, Tidow H, Rutherford TJ, Markwick P, Jensen MR, Mylonas E, Svergun DI, Blackledge M, Fersht AR (2008) Structure of tumor suppressor p53 and its intrinsically disordered N-terminal transactivation domain. Proc Natl Acad Sci USA 105:5762-5767

66. Dickinson ER, Jurneczko E, Nicholson J, Hupp TR, ZawackaPankau J, Selivanova G, Barran PE (2015) The use of ion mobility mass spectrometry to probe modulation of the structure of p53 and of MDM2 by small molecule inhibitors. Front Mol Biosci 2:39

67. Dickens MP, Fitzgerald R, Fischer PM (2010) Small-molecule inhibitors of MDM2 as new anticancer therapeutics. Sem Cancer Biol 20:10-18

68. Kussie PH, Gorina S, Marechal V, Elenbaas B, Moreau J, Levine AJ, Pavletich NP (1996) Structure of the MDM2 oncoprotein bound to the p53 tumor suppressor transactivation domain. Science 274:948-953

69. Pazgier M, Liu M, Zou G, Yuan W, Li C, Li C, Li J, Monbo J, Zella D, Tarasov SG, Lu W (2009) Structural basis for highaffinity peptide inhibition of p53 interactions with MDM2 and MDMX. Proc Natl Acad Sci USA 106:4665-4670

70. Shangary S, Wang S (2008) Targeting the MDM2-p53 interaction for cancer therapy. Clin Cancer Res 14:5318-5324

71. Shangary S, Wang S (2009) Small-molecule inhibitors of the MDM2-p53 protein-protein interaction to reactivate p53 function: a novel approach for cancer therapy. Ann Rev Pharmacol Toxicol 49:223-241

72. Vassilev LT (2007) MDM2 inhibitors for cancer therapy. Trends Mol Med 13:23-31

73. Yadahalli S, Neira JL, Johnson CM, Tan YS, Rowling PJE, Chattopadhyay A, Verma CS, Itzhaki LS (2019) Kinetic and thermodynamic effects of phosphorylation on p53 binding to MDM2. Sci Rep 9:693

74. Mallo GV, Fiedler F, Calvo EL, Ortiz EM, Vasseur S, Keim V, Morisset J, Iovanna JL (1997) Cloning and expression of the rat $\mathrm{p} 8 \mathrm{cDNA}$, a new gene activated in pancreas during the acute phase of pancreatitis, pancreatic development, and regeneration, and which promotes cellular growth. J Biol Chem 272:32360-32369

75. García-Montero A, Vasseur S, Mallo GV, Soubeyran P, Dagorn JC, Iovanna JL (2001) Expression of the stress-induced p8 mRNA is transiently activated after culture medium change. Eur J Cell Biol 80:720-725

76. Goruppi S, Iovanna JL (2010) Stress-inducible protein p8 is involved in several physiological and pathological processes. J Biol Chem 285:1577-1581

77. Malicet C, Dagorn JC, Neira JL, Iovanna JL (2006) p8 and prothymosin alpha: unity is strength. Cell Cycle 5:829-830

78. Malicet C, Giroux V, Vasseur S, Dagorn JC, Neira JL, Iovanna JL (2006) Regulation of apoptosis by the p8/prothymosin alpha complex. Proc Natl Acad Sci USA 103:2671-2676

79. Grasso D, Garcia MN, Hamidi T, Cano C, Calvo E, Lomberk G, Urrutia R, Iovanna JL (2014) Genetic inactivation of the pancreatitis-inducible gene Nupr1 impairs PanIN formation by modulating Kras(G12D)-induced senescence. Cell Death Differ 21:1633-1641
80. Sandi MJ, Hamidi T, Malicet C, Cano C, Loncle C, Pierres A, Dagorn JC, Iovanna JL (2011) p8 expression controls pancreatic cancer cell migration, invasion, adhesion, and tumorigenesis. J Cell Physiol 226:3442-3451

81. Ree AH, Pacheco MM, Tvermyr M, Fodstad O, Brentani MM (2000) Expression of a novel factor, com1, in early tumor progression of breast cancer. Clin Cancer Res 6:1778-1783

82. Hamidi T, Algul H, Cano CE, Sandi MJ, Molejon MI, Riemann M, Calvo E, Lomberk G, Dagorn JC, Weih F et al (2012) Nuclear protein 1 promotes pancreatic cancer development and protects cells from stress by inhibiting apoptosis. J Clin Invest 122:2092-2103

83. Cano CE, Hamidi T, García MN, Grasso D, Loncle C, García S, Calvo E, Lomberk G, Dusetti N, Bartholin L et al (2014) Genetic inactivation of Nupr 1 acts as a dominant suppressor event in a two-hit model of pancreatic carcinogenesis. Gut 63:984-995

84. Giroux V, Malicet C, Barthet M, Gironella M, Archange C, Dagorn JC, Vasseur S, Iovanna JL (2006) p8 is a new target of gemcitabine in pancreatic cancer cells. Clin Cancer Res 12:235-241

85. Palam LR, Gore J, Craven KE, Wilson JL, Korc M (2015) Integrated stress response is critical for gemcitabine resistance in pancreatic ductal adenocarcinoma. Cell Death Dis 6:e1913

86. Tang K, Zhang Z, Bai Z, Ma X, Guo W, Wang Y (2011) Enhancement of gemcitabine sensitivity in pancreatic cancer by co-regulation of dCK and p8 expression. Oncol Rep 25:963-970

87. Vasseur S, Hoffmeister A, García S, Bagnis C, Dagorn JC, Iovanna JL (2002) p8 is critical for tumour development induced by rasV12 mutated protein and E1A oncogene. EMBO Rep 3:165-170

88. Emma MR, Iovanna JL, Bachvarov D, Puleio R, Loria GR, Augello G, Candido S, Libra M, Gulino A, Cancila V et al (2016) NUPR1, a new target in liver cancer: implication in controlling cell growth, migration, invasion and sorafenib resistance. Cell Death Dis 7:e2269

89. Guo X, Wang W, Hu J, Feng K, Pan Y, Zhang L, Feng Y (2012) Lentivirus-mediated RNAi knockdown of NUPR1 inhibits human nonsmall cell lung cancer growth in vitro and in vivo. Anat Rec (Hoboken) 295:2114-2121

90. Kim KS, Jin DI, Yoon S, Baek SY, Kim BS, Oh SO (2012) Expression and roles of NUPR1 in cholangiocarcinoma cells. Anat Cell Biol 45:17-25

91. Li J, Ren S, Liu Y, Lian Z, Dong B, Yao Y, Xu Y (2017) Knockdown of NUPR1 inhibits the proliferation of glioblastoma cells via ERK1/2, p38 MAPK and caspase-3. J Neurooncol 132:15-26

92. Zeng C, Li X, Li A, Yi B, Peng X, Huang X, Chen J (2018) Knockdown of NUPR 1 inhibits the growth of U266 and RPMI8226 multiple myeloma cell lines via activating PTEN and caspase activation-dependent apoptosis. Oncol Rep 40:1487-1494

93. Zeng C, Yi B, Li X, Chen J (2017) Knockdown of nuclear protein 1 (NUPR1) gene inhibits proliferation and promotes apoptosis of human multiple myeloma U266 cells. Chin J Cell Mol Immunol 33:1240-1246

94. Zhou C, Xu J, Lin J, Lin R, Chen K, Kong J, Shui X (2018) Long non-coding RNA FEZF1-AS1 promotes osteosarcoma progression by regulating miR-4443/NUPR1 axis. Oncol Res Featur Preclin Clin Cancer Ther. https://doi.org/10.3727/096504018x 15188367859402

95. Encinar JA, Mallo GV, Mizyrycki C, Giono L, González-Ros JM, Rico M, Canepa E, Moreno S, Neira JL, Iovanna JL (2001) Human $\mathrm{p} 8$ is a HMG-I/Y-like protein with DNA binding activity enhanced by phosphorylation. J Biol Chem 276:2742-2751

96. Aguado-Llera D, Hamidi T, Doménech R, Pantoja-Uceda D, Gironella M, Santoro J, Velázquez-Campoy A, Neira JL, Iovanna 
JL (2013) Deciphering the binding between Nupr1 and MSL1 and their DNA-repairing activity. PLoS One 8:e78101

97. Neira JL, Rizzuti B, Iovanna JL (2016) Determinants of the pKa values of ionizable residues in an intrinsically disordered protein. Arch Biochem Biophys 598:18-27

98. Santofimia-Castaño P, Rizzuti B, Pey AL, Soubeyran P, Vidal M, Urrutia R, Iovanna JL, Neira JL (2017) Intrinsically disordered chromatin protein NUPR1 binds to the C-terminal region of Polycomb RING1B. Proc Natl Acad Sci USA 114:E6332-E6341

99. Santofimia-Castano P, Rizzuti B, Abián O, Velázquez-Campoy A, Iovanna JL, Neira JL (2018) Amphipathic helical peptides hamper protein-protein interactions of the intrinsically disordered chromatin nuclear protein 1 (NUPR1). Biochim Biophys Acta Gen Subj 1862:1283-1295

100. Neira JL, Bintz J, Arruebo M, Rizzuti B, Bonacci T, Vega S, Lanas A, Velázquez-Campoy A, Iovanna JL, Abián O (2017) Identification of a drug targeting an intrinsically disordered protein involved in pancreatic adenocarcinoma. Sci Rep 7:39732

101. Santofimia-Castano P, Xia Y, Lan W, Zhou Z, Huang C, Peng L, Soubeyran P, Velázquez-Campoy A, Abián O, Rizzuti B et al (2019) Ligand-based design identifies a potent NUPR1 inhibitor exerting anticancer activity via necroptosis. J Clin Invest $130: 2500-2513$
102. Santofimia-Castano P, Lan W, Bintz J, Gayet O, Carrier A, Lomberk G, Neira JL, González A, Urrutia R, Soubeyran P, Iovanna JL (2018) Inactivation of NUPR1 promotes cell death by coupling ER-stress responses with necrosis. Sci Rep 8:16999

103. Ruan H, Sun Q, Zhang W, Liu Y, Lai L (2019) Targeting intrinsically disordered proteins at the edge of chaos. Drug Discov Today 24:217-227

104. Jung LA, Gehbardt A, Koelmel W, Ade CP, Walz S, Kuper J, von Eyss B, Letscher S, Redel C, d'Artista L, Biankin A, Zender L, Sauer M, Wolf E, Evan G, Kisker C, Eilers M (2017) OmoMYC blunts promoter invasion by oncogenic MYC to inhibit gene expression characteristic of MYC-dependent tumors. Oncogene 36:1911-1924

105. DeLano WL (2002) The PyMOL molecular graphics system. DeLano Scientific, San Carlos

Publisher's Note Springer Nature remains neutral with regard to jurisdictional claims in published maps and institutional affiliations. 